\section{News@a glance}

Pandemic portal: Health Canada has launched a new Web site to serve as a "one-stop source of information" about pandemic influenza. The site, www.pandemicinfluenza.gc.ca, compiles information provided by the Public Health Agency of Canada and other federal departments, and includes the government's Pandemic Influenza Plan. Health Minister Tony Clement unveiled the site alongside CMA President Ruth Collins-Nakai and Jeff Poston, executive director of the Canadian Pharmacists Association. The CMA and $\mathrm{CPhA}$ will distribute kits containing information about seasonal influenza, avian flu and pandemic influenza to about 63000 health professionals.

Suing big tobacco: Manitoba has become the latest province to table legislation that would allow it to sue tobacco companies for the cost of treating people with smoking-related diseases. Health Minister Tim Sale estimates it costs more than \$Ioo million a year to treat tobacco-related illnesses in the province. He wants to be able to recoup that money, even if it means a major legal battle. Manitoba is serving notice on the tobacco industry that "the costs that they and their product have visited on our province over many years in the past, and unfortunately, will continue for years into the future, are their costs," Sale told the legislature when introducing the bill. The Tobacco Damages and
Health Care Costs Recovery Act would allow the government to file a lawsuit on behalf of any or all residents affected by tobacco-related illnesses. Manitoba follows British Columbia, Nova Scotia and New Brunswick, which have passed similar laws.

3 by 5 falls short: The United Nations' campaign to treat 3 million more HIVpositive people with anti-retroviral drugs did not achieve its goal, the World Health Organization and the Joint United Nations Programme on HIV/AIDS has concluded. The so-called " 3 by 5 " strategy was intended to expand access to HIV therapy for 3 million people in low- and middle-income nations by the end of 2005. But the strategy succeeded in getting more than triple the number of people on the drugs. In December 2003, there were 400000 people on anti-retrovirals in developing countries; by December 2005 that number had grown to I. 3 million. "Today, ' 3 by 5 ' has helped to mobilize political and financial commitment to achieving much broader access to treatment," Dr. Jong-wook Lee, the WHO's director-general, said in a news release. "This fundamental change in expectations is transforming our hopes of tackling not just HIV/AIDS, but other diseases as well."

Polio returns: Bangladesh is resuming polio vaccinations after finding its first case in March after nearly 6 years. A 9year-old girl, who became paralyzed,

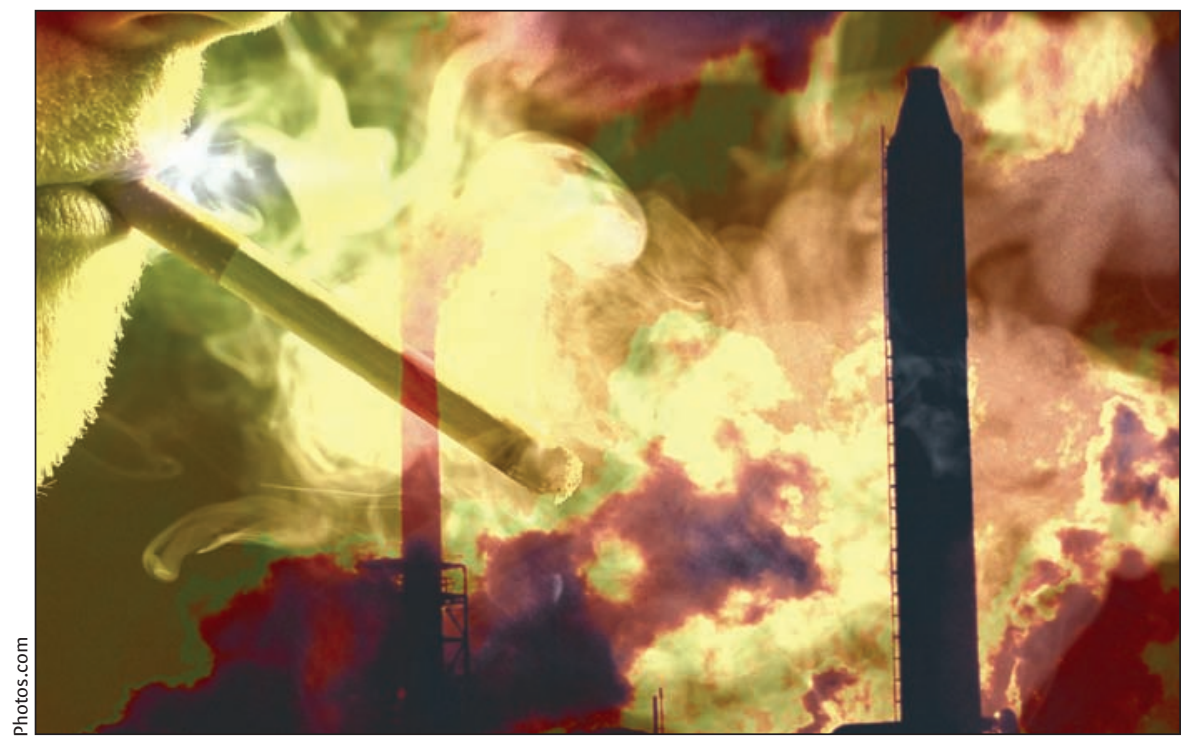

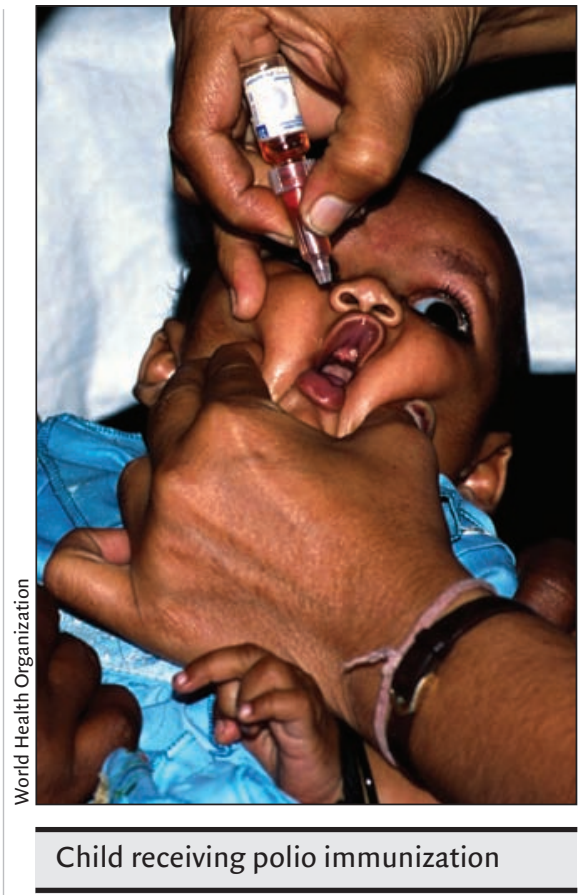

was the first person to get the disease since August 2000, according to the World Health Organization and the government of Bangladesh. Health officials believe the girl became infected after coming in contact with a family that had returned from Uttar Pradesh, an Indian state with confirmed cases of polio. Bangladesh planned 3 days of immunizations for all children under the age of 5 . Since 1988 , when the WHO began an anti-polio campaign, the number of people infected with polio worldwide dropped to 1880 in 2005, from more than 350000 cases previously.

Tumour bank: Cancer researchers around the world will now be able to obtain tissue samples from the Canadian Tumour Repository Network. The Network, financed by a 5-year, \$3.8million grant from the Canadian Institutes of Health Research, has more than 7000 samples available, about half of them breast cancer tumour samples. Cancer patients have voluntarily donated the samples, which are frozen in repositories in each province. The provincial centres are linked electronically. Researchers will be able to study why, for example, chemotherapy works well for some patients and not for others even if they suffer from the same type of cancer and are at the same stage 
of the disease. "We are trying to find out why this happens so that we can tailor treatment to individuals with greater certainty of success," Dr. Philip Branton, the scientific director of CIHR's Institute of Cancer Research, told a news conference announcing the tumour bank. Patients who donate samples will remain anonymous, and the Network's ethics board will approve any requests researchers make to use the samples. Compiled by Laura Eggertson, CMAJ

DOI:I0.1503/cmaj.060435

\section{Pulse}

\section{Marijuana use by tobacco}

\section{smokers and nonsmokers:}

\section{Who is smoking what?}

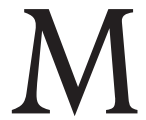

arijuana is often mixed with tobacco when smoked, and there is increasing evidence that its use by non-tobacco-smoking people may be a gateway to tobacco smoking. ${ }^{1}$ Using data from the 2004 Canadian Tobacco Use Monitoring Survey, ${ }^{2}$ we determined whether rates of marijuana use were similar among tobacco smokers and nonsmokers I5 years and older.

Of the respondents, $9 \%$ (2.4 million) reported using marijuana in the I2 months before the survey. In relation to tobacco smoking, $5 \%$ of those who never smoked cigarettes reported smoking marijuana in the 12 -month period (Fig. I). Those who identified themselves as current cigarette smokers had a substantially higher rate of marijuana use $(25 \%)$. The rates among current tobacco smokers were higher than the national average across all age groups, even in the oldest group. Of the respondents who were former cigarette smokers, $6 \%$ reported using marijuana; the highest rates of use in this group were among those aged $15-24$. This finding is important, since marijuana use by former smokers may increase their risk of smoking relapse.

The survey data suggest that marijuana use may represent a consider- able future public health burden if left unchanged. - Scott T. Leatherdale, Toronto, Ont.; Rashid Ahmed, Kitchener, Ont.; Murray Kaiserman, Ottawa, Ont.

This article has been peer reviewed.

\section{REFERENCES}

I. Patton GC, Coffey C, Carlin JB, et al. Reverse gateways? Frequent cannabis use as a predictor of tobacco initiation and nicotine dependence. Addict 2005;100:I5I8-25.

2. Canadian Tobacco Use Monitoring Survey, 2004. Ottawa: Health Canada. Available: www.hc-sc.gc .ca/hl-vs/tobac-tabac/research-recherche/stat/ctums -esutc/index_e.html (accessed 2006 Apr 3).

DOI:I0.I503/cmaj.05I6I4

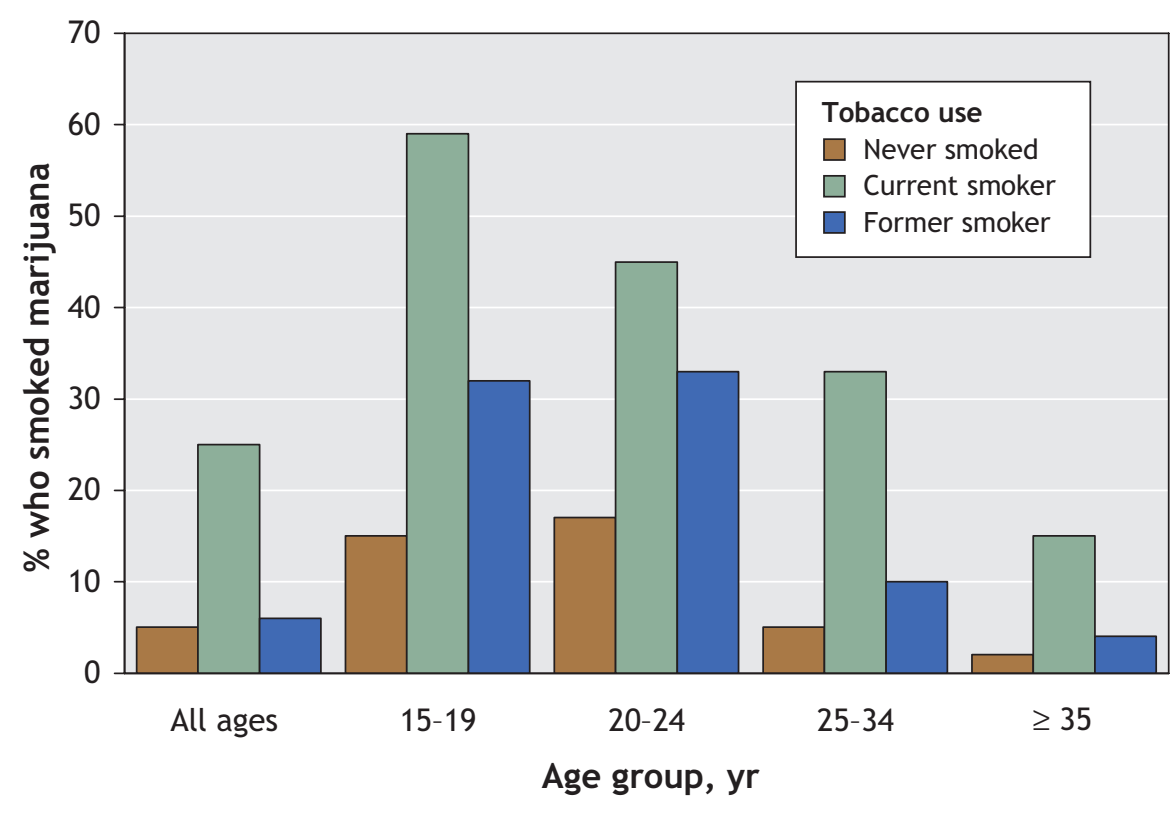

Fig. 1: Use of marijuana by tobacco smokers (current and former) and nonsmokers in Canada, by age group. Source: 2004 Canadian Tobacco Use Monitoring Survey. ${ }^{2}$ 